\title{
Longitudinal association of neighborhood variables with Body Mass Index in Dutch school-age children: The KOALA Birth Cohort Study
}

Citation for published version (APA):

Schmidt, S. C., Sleddens, E. F. C., de Vries, S. I., Gubbels, J., \& Thijs, C. (2015). Longitudinal association of neighborhood variables with Body Mass Index in Dutch school-age children: The KOALA Birth Cohort Study. Social Science \& Medicine, 135, 99-108. https://doi.org/10.1016/j.socscimed.2015.04.018

Document status and date:

Published: 01/01/2015

DOI:

10.1016/j.socscimed.2015.04.018

Document Version:

Publisher's PDF, also known as Version of record

\section{Document license:}

Taverne

Please check the document version of this publication:

- A submitted manuscript is the version of the article upon submission and before peer-review. There can be important differences between the submitted version and the official published version of record.

People interested in the research are advised to contact the author for the final version of the publication, or visit the DOI to the publisher's website.

- The final author version and the galley proof are versions of the publication after peer review.

- The final published version features the final layout of the paper including the volume, issue and page numbers.

Link to publication

\footnotetext{
General rights rights.

- You may freely distribute the URL identifying the publication in the public portal. please follow below link for the End User Agreement:

www.umlib.nl/taverne-license

Take down policy

If you believe that this document breaches copyright please contact us at:

repository@maastrichtuniversity.nl

providing details and we will investigate your claim.
}

Copyright and moral rights for the publications made accessible in the public portal are retained by the authors and/or other copyright owners and it is a condition of accessing publications that users recognise and abide by the legal requirements associated with these

- Users may download and print one copy of any publication from the public portal for the purpose of private study or research.

- You may not further distribute the material or use it for any profit-making activity or commercial gain

If the publication is distributed under the terms of Article $25 \mathrm{fa}$ of the Dutch Copyright Act, indicated by the "Taverne" license above, 


\title{
Longitudinal association of neighborhood variables with Body Mass Index in Dutch school-age children: The KOALA Birth Cohort Study
}

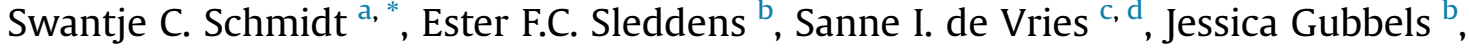 \\ Carel Thijs ${ }^{\mathrm{a}}$ \\ a Department of Epidemiology, School for Public Health and Primary Care (CAPHRI), Maastricht University, PO Box 616, 6200 MD Maastricht, \\ The Netherlands \\ ${ }^{\mathrm{b}}$ Department of Health Promotion, NUTRIM School for Nutrition and Translational Research in Metabolism, Maastricht University, PO Box 616, \\ 6200 MD Maastricht, The Netherlands \\ ${ }^{\mathrm{c}}$ Research Group Healthy Lifestyle in a Supporting Environment, The Hague University of Applied Sciences, PO Box 13336,2501 EH The Hague, \\ The Netherlands \\ d Netherlands Organisation for Applied Scientific Research, PO Box 2215, 2301 CE Leiden, The Netherlands
}

\section{A R T I C L E I N F O}

Article history:

Available online 30 April 2015

\section{Keywords:}

Netherlands

Neighborhood

Environment

Child

Obesity

Overweight

Birth Cohort

Generalized estimating equations

\begin{abstract}
A B S T R A C T
Changes in the neighborhood environment may explain part of the rapid increase in childhood overweight and obesity during the last decades. To date few theory-driven rather than data-driven studies have explored longitudinal associations between multiple neighborhood characteristics and child body weight development. We aimed to assess the relationship between physical, social and perceived safety related characteristics of the neighborhood and Body Mass Index (BMI) development in children during early school age, using a longitudinal design. We included an examination of moderating and confounding factors based on a conceptual model adapted from the EnRG framework (Environmental Research framework for weight Gain prevention) and empirical research. Analyses included 1887 children from the KOALA Birth Cohort Study followed from baseline age 4-5 years until 8-9 years. For children age 4-5 years, parents completed a questionnaire measuring characteristics of the neighborhood. Reliability and factor analyses were used to identify constructs for neighborhood characteristics. Linear regression analysis was performed to assess the relationship between neighborhood constructs and BMI z-scores cross-sectionally at age 4-5 years and longitudinally using Generalized Estimating Equations with BMI z-scores over 5 repeated measurements until age 8-9 years. Fourteen constructs were identified and grouped in three domains including perceived physical, social, or safety related characteristics of the neighborhood. Cross-sectionally, a lower BMI z-score was associated with higher perceived physical attractiveness of the neighborhood environment (standardized regression coefficient ( $\beta$ ) $-0.078,95 \% \mathrm{CI}-0.123$ to -0.034$)$ and a higher level of social capital $(\beta-0.142,-0.264$ to -0.019$)$. Longitudinally, similar associations were observed with potentially even stronger regression coefficients. This study suggests that BMI in children is mainly related to the modifiable physical and social environment of the conceptual model and not related to safety as perceived by parents.
\end{abstract}

(c) 2015 Elsevier Ltd. All rights reserved.

\section{Introduction}

The rapid increase in the prevalence of childhood overweight and obesity worldwide suggests the primary explanation for this trend is due to environmental rather than genetic factors (Law et al., 2007). Research on the association between the

\footnotetext{
* Corresponding author. Carl-Sonnenschein-Weg 13, 57250 Netphen, Germany.

E-mail address: Schmidt.swantje@gmail.com (S.C. Schmidt).
}

neighborhood environment and body weight is inherently complex. It constitutes interdisciplinary research, which involves a range of disciplines such as epidemiology, geography, sociology, behavioral and nutrition sciences, and economics. From a nutrition science perspective, different environmental characteristics influence energy balance-related behaviors, that is, energy intake and energy expenditure, which determine body weight (Kremers et al., 2006). In research, environmental characteristics are often broadly categorized as physical or social. From an urban planning perspective, the physical environment refers to the aspects such as 
building design, land use mix, and residential density (Foster and Giles-Corti, 2008). Yet from a sociological point of view, the former includes "the groups to which we belong, the neighborhoods in which we live, the organization of our workplaces, and the policies we create to order our lives" (Yen and Syme, 1999, p.287). Studies that direct focus to the influence of the social environment on overweight frequently look at cultural and normative constraints, socioeconomic characteristics, population density and turn over, support and networks or collective functioning (Casey et al., 2011).

A systematic umbrella review found no or at best preliminary support for the association between neighborhood patterns, land structure, urbanization characteristics, transportation, distances, socioeconomic and demographic characteristics, and obesity in adolescents and children. Preliminary support was only found for social characteristics such as relations with peers and physical activity. The authors concluded that there is a need for more studies to replicate the findings from previous research (Safron et al., 2011). For the social environment, a systematic review found that a lower deprivation and higher social capital were protective against adiposity in children (Carter and Dubois, 2010). No clear association between physical environmental characteristics and children's body weight was discerned due to reasons described below.

Overall, research on the relationship between the environment and body weight is characterized by methodological and theoretical shortcomings as well as heterogeneity in study designs (Black and Macinko, 2008; Booth et al., 2005; Carter and Dubois, 2010; Feng et al., 2010; Safron et al., 2011). First, many studies lack a theoretical framework that informs statistical modeling approaches (Carter and Dubois, 2010). Second, most studies employ a cross-sectional design, including those based on cohort research, meaning that potential causal pathways cannot be explored (Black and Macinko, 2008; Carter and Dubois, 2010; Feng et al., 2010). Third, few studies clearly identify confounders, effect modifiers, and mediators for causal pathways (Feng et al., 2010). For children, research evidence suggests that breastfeeding, gestational age, birth weight, mother's pre-pregnancy BMI, and parental smoking during pregnancy should be considered potential confounders in the relationship between environmental characteristics and adiposity (Dubois and Girard, 2006; Oken and Gillman, 2003; Power and Jefferis, 2002). In addition, the child's age should be included as an effect modifier because the importance of surroundings increases with age as children become more independent. Likewise, parents may allow younger children to play outside when older siblings supervise them. Gender could furthermore be an important effect modifier because perceptions of safety and hence use of the neighborhood environment may differ for boys and girls. A further difficulty in judging previous research is that different measurement methods have been used to assess characteristics of the environment, which adds to the heterogeneity in study designs (Carter and Dubois, 2010).

In this study, we investigate the association between perceived social, physical, and safety related characteristics of the neighborhood and Body Mass Index (BMI) in children employing crosssectional and longitudinal analyses. The current study seeks to overcome some of the aforementioned shortcomings of existing research studies. Firstly, we constructed a conceptual model (Fig. 1) based on the EnRG framework as well as empirical research from various disciplines to formulate research hypotheses and guide our statistical analyses. The EnRG framework sees energy balancerelated behavior, namely energy intake and energy expenditure, as the result of conscious and unconscious processes, which stem from different levels and types of environmental factors, cognitive mediators, and person and behavior related moderators (Kremers et al., 2006). Our conceptual model separates the neighborhood into perceived social, physical and safety related characteristics, which determine body weight through energy balance-related behaviors that are moderated by child characteristics (e.g. age) as well as over time by a changing environment. Moreover, confounding factors pertaining to the child and parents (e.g. birth weight, maternal smoking) affect the relationship between the neighborhood and body weight in children. In the context of our conceptual model, we hypothesize that there is a cross-sectional and longitudinal association between perceived physical (e.g., availability of areas or facilities for exercise within $10 \mathrm{~min}$ ), social (social capital), and safety-related (e.g., social safety, nuisance and small scale crime) neighborhood characteristics to BMI in children with baseline age $4-5$ years as well as BMI development over 5 repeated measurements until the age of 8-9 years.

By employing this longitudinal design, the current study enables the examination of potential causal pathways, overcoming the shortcomings that the previous cross-sectional studies face. Moreover, based on the conceptual model a systematic examination of confounding, effect modification, and mediation is included, which is often lacking in previous research. Our rationale for studying the current age group is twofold. From a sociological and developmental point of view, children aged $4-5$ years fall into the early school age; the time period in which children start to increasingly use the neighborhood environment. Therefore, the neighborhood environment provides opportunities for physical activity, which can have an increasing long-term influence on BMI. Moreover, follow-up from this baseline age for 5 years captures the so-called critical or sensitive period of overweight development. According to Dietz (1994) the risk of long-term adiposity and resulting complications have been linked to three critical periods during childhood. Among these is a so-called adiposity rebound period, which concerns the age at which BMI is lowest and then begins to rise again. This is observed in children between age 5 and 7. In a review of the growth trajectories leading to adult obesity, Rolland-Cachera and Péneau (2013) identified two patterns; one with high BMI throughout childhood and one with ongoing BMI increase after an early adiposity rebound. For this reason, we focused on BMI cross-sectionally as well as the change from baseline during follow-up.

\section{Methods}

\subsection{Participants and procedures}

This study was part of the KOALA Birth Cohort Study (Dutch acronym for Child, Parent and Health: Lifestyle and Genetic Constitution), a prospective cohort study. Healthy pregnant women were recruited from an existing cohort on pregnancy-related pelvic girdle pain between 2000 and 2002 (conventional recruitment group) and through alternative channels from organic food shops, Steiner schools, anthroposophic doctors and midwives, and dedicated magazines between 2000 and 2001 (alternative recruitment group) (Kummeling et al., 2005). Ethical approval was obtained from the medical ethics committee of the Maastricht University hospital and all parents signed informed consent forms.

The KOALA Birth Cohort Study initially included 2834 children living in the south of the Netherlands or its border region of an adjacent country. Children suffering from congenital anomalies were excluded from data analyses due to their potential inability to use the neighborhood environment or medication intake biasing BMI. Second born twins were also excluded from the analysis given that these children share the same environment. Children living elsewhere more than three days per week (in the case of divorced parents) were also excluded because of the limited presence in the neighborhood environment of their residence address. The study 


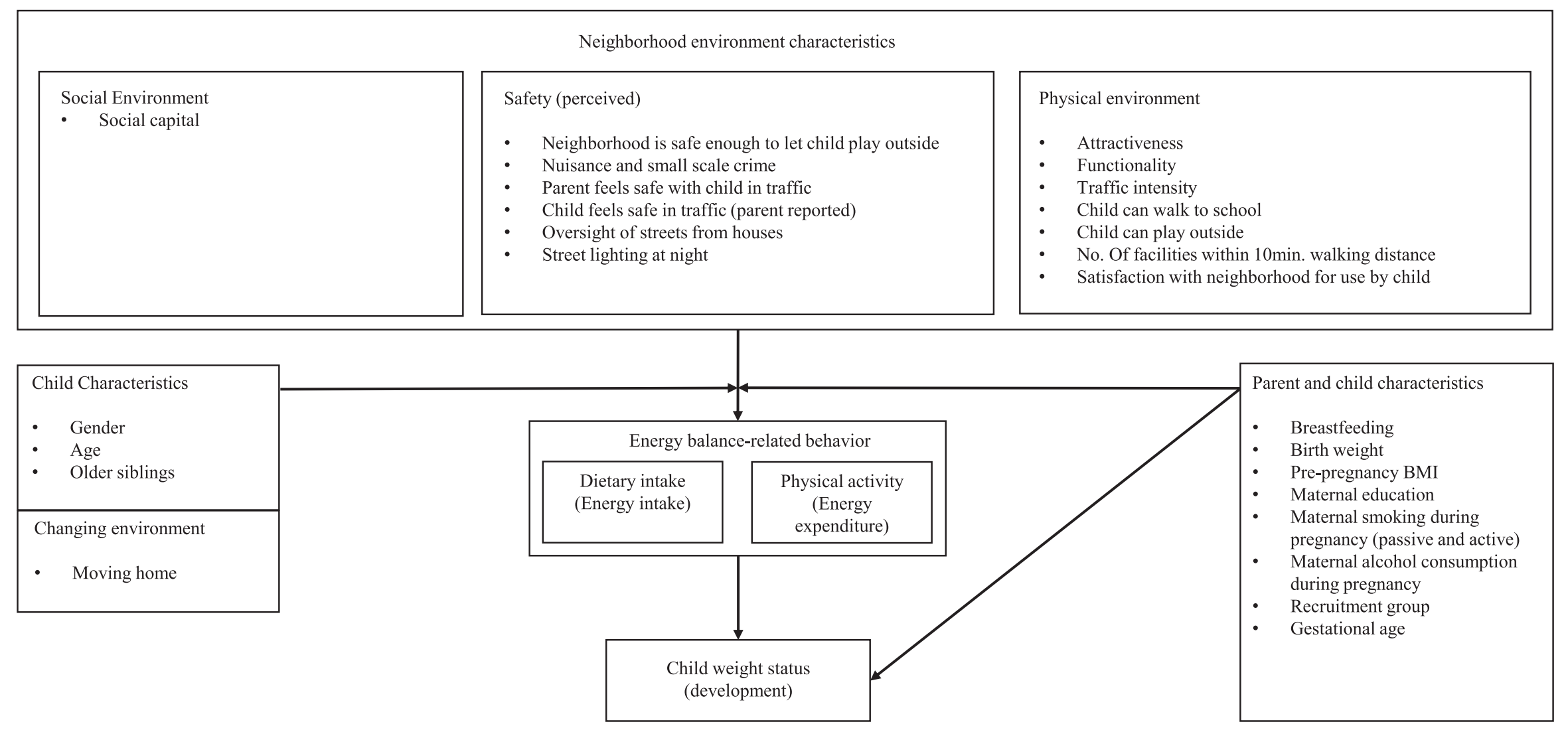

Fig. 1. Conceptual model for relationships between neighborhood characteristics and BMI development in children: authors' compilation and adaptation from Kremers et al. (2006). 
included 1887 children in the cross-sectional analysis (i.e. at baseline age $4-5$ years).

\subsection{Measurement of the neighborhood environment}

When children were $4-5$ years old, parents completed a questionnaire assessing characteristics of the neighborhood environment. The questionnaire included 48 items measuring perceived physical and social aspects of the neighborhood environment using Likert and ordinal scales. For example, the level of agreement with statements like "Most streets in the neighborhood have cycle paths" or "The neighborhood is a real community" was measured on a five-point scale ranging from "I strongly disagree" to "I strongly agree". The construction of the questionnaire was informed by previous methodological research, which, for example, tested the reliability of different questionnaires measuring the 'physical activity-friendliness' of the environment (Brownson et al., 2004). Items were adjusted to one direction, if necessary, and sumscores computed to arrive at themes like safety, accessibility, functionality, attractiveness, and social capital (Addy et al., 2004; Brownson et al., 2004; Cervero and Duncan, 2003; Crane and Crepeau, 1998; Giles-Corti and Donovan, 2003; Kirtland et al., 2003). Two sum-score constructs (social capital and satisfaction of the parent with the neighborhood) indicated two peaks in the distribution; thus three categories (low, medium, high) were computed for these constructs.

\subsection{Covariates}

Confounders and effect modifiers were assessed at different points in time. The following confounders were measured prior to baseline measurement, i.e., before child's age 4-5 years: gestational age in weeks and birth weight in grams, height and weight of the mother (used to calculate the mother's pre-pregnancy BMI), maternal smoking (cigarettes/day) and alcohol consumption during pregnancy (glasses/week) (questionnaires at 14 and 34 weeks of pregnancy), and duration of breast and formula feeding (questionnaires at 2 weeks, 3, 6, 7 and 12 months post-partum). At baseline (4-5 years) presence of older siblings, highest maternal education, and the exact age of the child at that time were assessed. Moving home during the follow-up was captured by a change in the residence address from the baseline age $4-5$ years onwards and included as a covariate in the longitudinal analysis. Residential mobility results in differential exposure lengths, which could attenuate the effect of the neighborhood environment on children's BMI development. T-tests and chi-square tests indicated no differences in the distribution of covariates between movers and nonmovers except for having older siblings, which were more often present in the group of non-movers.

\subsection{Outcome measure}

Parents were asked to measure their child's body weight (in kilograms with one decimal) and height (in centimeters), measuring the child while wearing light clothes and no shoes, and to report the exact measurement date along with the age of the child. BMI was calculated from these measurements as the child's weight in kilograms divided by the squared height in meters $(\mathrm{kg} /$ $\mathrm{m}^{2}$ ). The mean age of the children at the measurement instances were $60.14,77.79,86.32$, 98.03 and 109.48 months. BMI was standardized into z-scores for age and gender using the Dutch reference population surveyed in 1996-1997 (Fredriks et al., 2000).

\subsection{Statistical analysis}

Data analysis was carried out in SPSS 19 (SPSS Inc, Chicago, II, USA). Reliability analyses were used to confirm the presence of constructs in the initial grouping of neighborhood variables by calculating simple correlations and Cronbach's alpha depending on the amount of items expected to measure a construct. A Cronbach's alpha between 0.70 and 0.80 has been suggested to present an acceptable value, but this value is strongly dependent on the number of items (Field, 2009). Therefore, some constructs with a value above 0.60 have also been included. If expected constructs did not emerge or individual variables did not contribute to a particular construct, principal component analysis (PCA) was performed to further explore the presence of constructs within and between the initial groupings of variables. For PCA, constructs that emerged also had to yield a Cronbach's alpha exceeding 0.60 , depending on the number of items. Otherwise items were included as single item constructs. Composite variables measuring constructs were calculated as sum scores. Person mean imputation was used to deal with missing values on constructs, where a criterion for each construct was specified depending on the number of items.

We assessed multicollinearity with the help of correlation matrices, variance inflation factors (VIF) and condition indices. No correlation matrices showed higher than intermediate correlations $(R<0.7)$. The average VIF was well above 1 , which has been suggested as a potential indicator of a multicollinearity problem (Field, 2009). However, multicollinearity is claimed to be a small problem if the condition index remains below 30 (Kleinbaum et al., 2008). No condition indices exceeded the value 7.4 , so overall multicollinearity can mainly be attributed to dummy variables with small, if any, influences on regression parameter estimates.

Linear regression analyses were performed to investigate the cross-sectional relationship between neighborhood characteristics and BMI in children aged 4-5 years. First, the association between individual neighborhood variables and BMI z-score was explored in simple linear regression (Model 1). A separate model was built including only confounders to explore their relationship with BMI z-score. In line with Rothman et al. (2008), we considered a $10 \%$ change in the beta coefficient of the neighborhood variable in the multiple compared to a simple linear regression model as confounding. Variables not meeting this criterion were removed from the models. Second, each individual neighborhood variable was entered into a multiple regression model along with confounders that emerged from the previous step (Model 2). To test for interaction, we included interaction terms for each potential effect modifier with the neighborhood variable in Model 2. Third, all neighborhood variables falling into one domain of the neighborhood environment (perceived physical, social or safety, Fig. 1), were entered into a multiple regression model with confounders and interaction terms. This resulted in three multiple regression models (Model 3), one for each domain. To avoid attenuation of effects by the hypothesized intermediate neighborhood variables related to perceived safety (Fig. 1), the three domains were not merged into one model.

Linear regression with generalized estimating equations (GEE) was used to assess the development of BMI z-score in children over the five repeated measurements. GEE corrects for correlated errors in repeated measurements (Twisk, 2006). To choose the appropriate correlation structure, simple correlations between BMI zscore values were calculated. Correlation coefficients ranged between 0.65 and 0.75 with no large differences between adjacent and more distant measurements in time. Therefore, the exchangeable correlation structure, also referred to as compound symmetry, was chosen. Literature suggests that GEE is fairly robust against deviations from the most appropriate correlation structure 
(Liang and Zeger, 1986). The same approach of building Models 1, 2 and 3 as in the cross-sectional linear regression analysis was then used for GEE.

Both cross-sectional and longitudinal models were tested for the effect modification by gender and the presence of older siblings between environmental characteristics and weight (development) by including interaction terms between each neighborhood variable and the potential effect modifier in the adjusted models (Model 2). Longitudinally, moving home was another effect modifier. A p-value of 0.05 was used as the criterion for determining the presence of interaction. Significant interactions were explored further through stratified analyses. Moreover, cross-sectionally, interaction terms for age at baseline were included in the model comprising confounders to assess whether the association between neighborhood variables and BMI z-score differs by age (Model 2). In GEE, interaction with time was tested by including an interaction term for each neighborhood variable with the child's age in months (Model 2).

All regression results are expressed as standardized beta coefficients unless indicated otherwise. This means that a beta coefficient of 0 indicates no association and a beta coefficient of 1 shows that a one standard deviation higher or lower of the neighborhood variable is associated with $\times$ standard deviation change (increase or decrease) in the BMI z-score. In the results section, unadjusted and adjusted analyses are presented. Whereas adjusted models include covariates, unadjusted models only include the neighborhood environment variables.

\section{Results}

Cross-sectional analyses, i.e. baseline measurement, included 1887 children and longitudinal analyses included 1730 children (of which 293 moved home after the baseline measurement). Sample characteristics for the baseline measurement are presented in Table 1. The children's mean age at baseline was 60.18 months (5.01 years). The average BMI at baseline was 15.23 ( $\mathrm{SD}=1.39$ ), which was equivalent to a BMI z-score of -0.27 $(\mathrm{SD}=0.99)$. Reliability analyses and principal component analysis led to the identification of 42 items out of 48 items in the questionnaire, which were included to form single or multiple item constructs. Items not included in the analysis either had many missing values (e.g., distance to water) or were thought be less relevant constructs in the context of this study (e.g., "nuisance or small scale crime do not make the neighborhood unsafe at night"). In total, 14 constructs were included in the analysis of which 8 were single item and 6 multiple item constructs as shown in Table 2.

\subsection{Cross-sectional association of neighborhood variables with BMI $z$-score}

Table 3 shows the results from simple and multiple linear regression analyses. In the perceived physical environment domain, attractiveness showed an inverse association with BMI z-score at child's age 4-5 years. The inverse association was similar in the unadjusted and adjusted analysis. In the model including all neighborhood variables related to the perceived physical environment and covariates (Model 3), a one standard deviation increase in attractiveness was associated with a 0.078 lower BMI z-score. BMI z-score consistently decreased with increasing satisfaction with the neighborhood environment $(\mathrm{p}=0.022)$, indicating a 0.159 lower BMI $z$-score in the highest category (Model 2). This means that there was a linear decrease in the beta coefficient for satisfaction over the three categories.

Table 1

Sample characteristics $(\mathrm{N}=1887)$.

\begin{tabular}{|c|c|c|}
\hline Variable & $\%$ or mean $(\mathrm{SD})$ & Missing \\
\hline \multicolumn{3}{|l|}{ Gender (\%) } \\
\hline Male & 50.9 & \\
\hline Female & 49.1 & \\
\hline BMI z-score $\left(\mathrm{kg} / \mathrm{m}^{2}\right) 4-5$ years & $-0.27(0.99)$ & \\
\hline Age in months & $60.18(6.45)$ & \\
\hline \multicolumn{3}{|l|}{ Maternal education level } \\
\hline Primary school \& lower vocational (\%) & 34.9 & \\
\hline Secondary school (\%) & 10.2 & \\
\hline Higher vocational (\%) & 36.0 & \\
\hline University (\%) & 14.3 & \\
\hline Other and missing (\%) & 4.6 & \\
\hline \multicolumn{3}{|l|}{ Breast and bottle feeding } \\
\hline Artificial formula feeding from birth (\%) & 15.0 & \\
\hline Breast and formula feeding in first 3 months (bottle introduced before 4 th month) (\%) & 40.4 & \\
\hline Breastfeeding as only milking feeding in first 3 months (not accounting for solids) (\%) & 23.8 & \\
\hline Breastfeeding as only milking feeding in first 6 months (not accounting for solids) (\%) & 20.8 & \\
\hline Gestational age (weeks) & $39.52(1.46)$ & \\
\hline Birth weight (grams) & $3527.73(497.01)$ & $1^{\mathrm{b}}$ \\
\hline Maternal pre-pregnancy BMI & $23.67(3.78)$ & $6^{\mathrm{b}}$ \\
\hline Maternal smoking 34th week of pregnancy (cigarettes/week) & $0.45(2.24)$ & \\
\hline Maternal passive smoking 34th week of pregnancy & & $7^{\mathrm{a}}$ \\
\hline$<1 \mathrm{~h} /$ week $(\%)$ & 66.6 & \\
\hline$<1 \mathrm{~h} /$ day $(\%)$ & 23.2 & \\
\hline 1 and $4 \mathrm{~h}$ per day & 8.3 & \\
\hline$>5 \mathrm{~h} /$ day & 2.0 & \\
\hline Alcohol consumption during pregnancy (glasses/week) & $0.29(0.81)$ & \\
\hline Older siblings (\%) & 55.7 & \\
\hline Moved home $(\%)^{c}$ & 17.2 & \\
\hline Conventional recruitment group (\%) & 82.0 & \\
\hline
\end{tabular}

${ }^{a}$ Median substitution.

b Mean substitution.

c Percentage is based on the sample size in longitudinal analyses $(\mathrm{N}=1730)$ including cases with at least one repeated standardized BMI measurement after baseline and no residential mobility to another country (except border region). 
Table 2

Results reliability and principal component analyses: constructs measuring social, physical and perceived safety characteristics of the neighborhood environment ( $\mathrm{N}=1887$ ).

\begin{tabular}{|c|c|c|c|c|}
\hline Construct & Items & $\begin{array}{l}\text { Cronbach's } \\
\text { alpha }\end{array}$ & Mean (SD) & $\begin{array}{l}\text { Missing } \\
\text { values }\end{array}$ \\
\hline \multicolumn{5}{|l|}{ Perceived safety: } \\
\hline The street have good street lighting at night ${ }^{a}$ & Single item (5-point ordinal scale) & $\mathrm{n} / \mathrm{a}$ & $3.92(0.89)$ & 0 \\
\hline Pedestrians/cyclists can easily be seen from houses & Single item (5-point ordinal scale) & $\mathrm{n} / \mathrm{a}$ & $3.71(0.95)$ & $3^{b}$ \\
\hline $\begin{array}{l}\text { Nuisance and small scale crime do not make the } \\
\text { neighborhood unsafe during daytime }\end{array}$ & Single item (5-point ordinal scale) & $\mathrm{n} / \mathrm{a}$ & $4.62(0.64)$ & 1 \\
\hline $\begin{array}{l}\text { The neighborhood is safe enough to let the child } \\
\text { walk or play in the street (without supervision) }\end{array}$ & Single item (5-point ordinal scale) & & $3.34(1.27)$ & 1 \\
\hline $\begin{array}{l}\text { Parent feels safe walking or cycling with child in the } \\
\text { neighborhood }\end{array}$ & Single item (4-point ordinal scale) & $\mathrm{n} / \mathrm{a}$ & $2.06(0.64)$ & $10^{\mathrm{b}}$ \\
\hline $\begin{array}{l}\text { Child feels safe walking or cycling in the } \\
\text { neighborhood }\end{array}$ & Single item (4-point ordinal scale) & $\mathrm{n} / \mathrm{a}$ & $1.95(0.67)$ & $17^{\mathrm{b}}$ \\
\hline \multicolumn{5}{|l|}{ Physical/built environment: } \\
\hline No. of facilities within 10 min walking distance & $\begin{array}{l}\text { 6-item score calculated from number of } \\
\text { facilities/areas for exercise within } 10 \text { min } \\
\text { walking distance (forest, school, } \\
\text { playground, playing field (unpaved), } \\
\text { gym or facility for exercise, swimming pool) } \\
\text { (7-point ordinal scale) }\end{array}$ & $\mathrm{n} / \mathrm{a}$ & $3.40(1.52)$ & $\mathrm{n} / \mathrm{a}$ \\
\hline Child can easily walk/cycle from home to school & Single item (5-point ordinal scale) & $\mathrm{n} / \mathrm{a}$ & $3.87(1.59)$ & $3^{\mathrm{b}}$ \\
\hline $\begin{array}{l}\text { Child can play outside with friends in } \\
\text { walking distance }\end{array}$ & Single item (5-point ordinal scale) & $\mathrm{n} / \mathrm{a}$ & $4.48(1.02)$ & $1^{\mathrm{b}}$ \\
\hline Low traffic intensity & $\begin{array}{l}\text { 4-item sum score: speed of traffic (max } 30 \mathrm{~km} / \mathrm{h} \text { ), } \\
\text { exhausts, ability of child to play outside with regard } \\
\text { to traffic, compliance with speed limit } \\
\text { (Continuous variable) }\end{array}$ & 0.740 & $\begin{array}{l}13.03 \\
(3.85)\end{array}$ & $1^{\mathrm{b}}$ \\
\hline Functionality & $\begin{array}{l}\text { 6-item sum score: availability of footpaths and stairs, } \\
\text { maintenance of footpaths, separation of footpaths from } \\
\text { streets, } \\
\text { availability of cycle paths, separation of cycle paths from } \\
\text { streets, } \\
\text { availability of different routes (Continuous variable) }\end{array}$ & 0.643 & $\begin{array}{l}17.99 \\
(4.98)\end{array}$ & 13 \\
\hline Attractiveness & $\begin{array}{l}\text { 7-item sum score: availability of green, amount of litter, } \\
\text { presence of residential blocks, presence of } \\
\text { detached houses, presence of abandoned houses, amount } \\
\text { of noise, amount of dog feces (Continuous variable) }\end{array}$ & 0.664 & $\begin{array}{l}27.55 \\
(4.00)\end{array}$ & $1^{\mathrm{c}}$ \\
\hline \multirow[t]{4}{*}{$\begin{array}{l}\text { Satisfaction of parent with neighborhood } \\
\text { for use by child }\end{array}$} & $\begin{array}{l}\text { 3-item sum score: satisfaction with opportunities to } \\
\text { play outside, satisfaction with opportunities to walk, } \\
\text { satisfaction with opportunity to cycle } \\
\text { (5-point-ordinal scale) } \\
3 \text { categories }\end{array}$ & 0.845 & $\begin{array}{l}11.38 \\
(2.78)\end{array}$ & 0 \\
\hline & Low satisfaction (\%) & $\mathrm{n} / \mathrm{a}$ & 39.9 & \\
\hline & Intermediate satisfaction (\%) & $\mathrm{n} / \mathrm{a}$ & 36.9 & \\
\hline & High satisfaction (\%) & $\mathrm{n} / \mathrm{a}$ & 23.1 & \\
\hline \multicolumn{5}{|l|}{ Social environment: } \\
\hline \multirow[t]{4}{*}{ Social capital } & $\begin{array}{l}\text { 5-item sum score: willingness to help each other in } \\
\text { neighborhood, presence of community, trust in } \\
\text { neighborhood, getting along in neighborhood, sharing of } \\
\text { norms and values (5-point ordinal scale) } \\
3 \text { categories }\end{array}$ & 0.871 & $\begin{array}{l}19.12 \\
(3.21)\end{array}$ & $1^{\mathrm{c}}$ \\
\hline & Intermediate social capital (\%) & $\mathrm{n} / \mathrm{a}$ & 40.0 & \\
\hline & Low social capital (\%) & $\mathrm{n} / \mathrm{a}$ & 40.5 & \\
\hline & High social capital (\%) & $\mathrm{n} / \mathrm{a}$ & 19.5 & \\
\hline
\end{tabular}

\footnotetext{
a Principal component analysis was used to identify this construct.

b Variable median substitution was used to impute missing values.

c Case mean substitution was used to impute missing values based on criteria devised for each construct (traffic intensity: $2 / 4$; oversight of streets: $1 / 2$; functionality: no

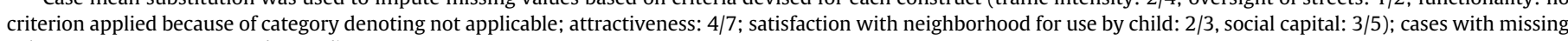
values on sum scores were dropped).
}

However, the association became insignificant in the most complete model comprising all neighborhood variables of the perceived physical environment domain (Model 3). Therefore, the association of satisfaction with BMI z-score was changed by the other variables of the perceived physical neighborhood environment. Instead, perceptions of opportunities for playing outside became associated with higher BMI in this model (Table 3, Model 3). In the social environment, perceived social capital in the highest versus lowest category was inversely associated with BMI z-score in all linear regression models, with a 0.143 lower BMI z-score (Model 2 and 3).

\subsection{Longitudinal association of neighborhood variables with BMI z- score}

Table 4 shows that the perceived safety constructs were not associated with the child's BMI in the longitudinal analysis (like the cross-sectional analysis). In the perceived physical environment domain, longitudinal results were very similar to cross-sectional results: perceived attractiveness of the neighborhood environment, high satisfaction and the possibility to play outside with friends was related to a lower BMI z-score. In addition, two other factors became statistically significantly associated with lower BMI: 
Table 3

Association between neighborhood and child's BMI z-score at $4-5$ years of age ( $\mathrm{N}=1887$ ).

\begin{tabular}{|c|c|c|c|c|c|c|}
\hline \multirow[t]{2}{*}{ Construct } & \multicolumn{2}{|l|}{ Model 1} & \multicolumn{2}{|l|}{ Model 2} & \multicolumn{2}{|l|}{ Model 3} \\
\hline & $\beta$ & $95 \% \mathrm{CI}$ & $\beta$ & $95 \% \mathrm{CI}$ & $\beta$ & $95 \% \mathrm{CI}$ \\
\hline \multicolumn{7}{|l|}{ Perceived safety: } \\
\hline Little nuisance/small scale crime during daytime & -0.040 & $-0.085,0.005$ & -0.023 & $-0.067,0.020$ & -0.018 & $-0.062,0.026$ \\
\hline Neighborhood is safe enough to let child play & -0.031 & $-0.076,0.013$ & -0.032 & $-0.075,0.012$ & -0.036 & $-0.085,0.012$ \\
\hline Parent feels safe walking or cycling with child & 0.010 & $-0.034,0.055$ & 0.010 & $-0.033,0.053$ & 0.004 & $-0.046,0.055$ \\
\hline Child feels safe walking or cycling & -0.013 & $-0.058,0.032$ & 0.000 & $-0.043,0.044$ & -0.009 & $-0.058,0.040$ \\
\hline Good visibility of pedestrians and cyclists from houses & 0.013 & $-0.032,0.057$ & 0.012 & $-0.031,0.055$ & 0.041 & $-0.013,0.095$ \\
\hline Good Street lighting at night ${ }^{\mathrm{b}}$ & -0.016 & $-0.061,0.029$ & -0.019 & $-0.062,0.024$ & -0.033 & $-0.085,0.020$ \\
\hline \multicolumn{7}{|l|}{ Physical environment: } \\
\hline No. of facilities within 10 min walking distance & -0.024 & $-0.069,0.020$ & -0.016 & $-0.060,0.027$ & -0.013 & $-0.062,0.036$ \\
\hline Child can walk to school & 0.022 & $-0.023,0.067$ & 0.013 & $-0.031,0.057$ & 0.019 & $-0.031,0.069$ \\
\hline Child can play outside with friends & 0.019 & $-0.026,0.064$ & 0.027 & $-0.016,0.070$ & $\mathbf{0 . 0 5 3}^{*}$ & $0.005,0.101$ \\
\hline Low traffic intensity & -0.020 & $-0.065,0.024$ & -0.022 & $-0.066,0.021$ & 0.025 & $-0.028,0.078$ \\
\hline Functionality & -0.043 & $-0.087,0.002$ & -0.037 & $-0.081,0.006$ & -0.045 & $-0.092,0.002$ \\
\hline Attractiveness & $-0.078^{* *}$ & $-0.123,-0.034$ & $-0.075^{* *}$ & $-0.118,-0.032$ & $-0.078^{* *}$ & $-0.127,-0.028$ \\
\hline \multicolumn{7}{|c|}{ Satisfaction with the neighborhood environment (low = reference) } \\
\hline Intermediate $^{a}$ & -0.093 & $-0.196,0.009$ & -0.092 & $-0.190,0.006$ & -0.097 & $-0.207,0.013$ \\
\hline High $^{a}$ & $-0.135^{*}$ & $-0.253,-0.018$ & $-0.159^{* *}$ & $-0.272,-0.046$ & -0.125 & $-0.263,0.013$ \\
\hline \multicolumn{7}{|l|}{ Social environment: } \\
\hline \multicolumn{7}{|l|}{ Social capital (low = reference) } \\
\hline Medium $^{\mathrm{a}}$ & -0.011 & $-0.111,0.090$ & -0.042 & $-0.139,0.055$ & -0.042 & $-0.139,0.055$ \\
\hline High $^{\mathrm{a}}$ & $-0.142^{*}$ & $-0.264,-0.019$ & $-0.143^{*}$ & $-0.262,-0.025$ & $-0.143^{*}$ & $-0.262,-0.025$ \\
\hline
\end{tabular}

${ }^{*} \mathrm{p}<0.05$.

${ }^{* *} \mathrm{p}<0.01$.

${ }^{* * *} \mathrm{p}<0.001, \beta$ is the standardized regression coefficient (unless indicated otherwise).

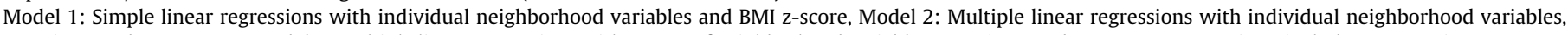

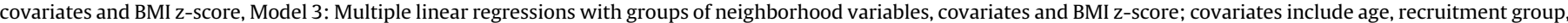

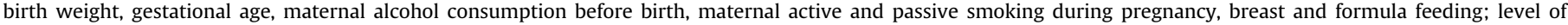
maternal education not included.

Significant results are additionally highlighted with bold letters.

a Unstandardized beta coefficient.

b Interaction with older siblings in simple linear regression (Model 2).

Table 4

Longitudinal relationship between baseline neighborhood (child's age $4-5$ years) and repeated BMI z-score over $4-5$ years ( $\mathrm{N}=1730)$.

\begin{tabular}{|c|c|c|c|c|c|c|}
\hline \multirow[t]{2}{*}{ Construct } & \multicolumn{2}{|l|}{ Model 1} & \multicolumn{2}{|l|}{ Model 2} & \multicolumn{2}{|l|}{ Model 3} \\
\hline & $\beta$ & $95 \% \mathrm{CI}$ & $\beta$ & $95 \% \mathrm{CI}$ & $\beta$ & $95 \% \mathrm{CI}$ \\
\hline \multicolumn{7}{|l|}{ Perceived safety: } \\
\hline Little nuisance/small scale crime during daytime ${ }^{\mathrm{b}}$ & -0.033 & $-0.071,0.004$ & -0.016 & $-0.052,0.021$ & -0.008 & $-0.044,0.029$ \\
\hline Neighborhood is safe enough to let child play & -0.031 & $-0.069,0.008$ & $-0.038^{*}$ & $-0.074,-0.001$ & -0.039 & $-0.080,0.001$ \\
\hline Parent feels safe walking or cycling with child ${ }^{\mathrm{C}}$ & 0.010 & $-0.030,0.049$ & 0.010 & $-0.027,0.047$ & -0.004 & $-0.046,0.037$ \\
\hline Child feels safe walking or cycling & -0.005 & $-0.044,0.035$ & 0.008 & $-0.030,0.046$ & -0.001 & $-0.041,0.040$ \\
\hline Good visibility of pedestrians and cyclists from houses & -0.001 & $-0.039,0.038$ & 0.000 & $-0.036,0.036$ & 0.035 & $-0.009,0.079$ \\
\hline Good Street lighting at night & -0.035 & $-0.073,0.003$ & -0.031 & $-0.067,0.005$ & -0.042 & $-0.085,0.001$ \\
\hline \multicolumn{7}{|l|}{ Physical environment: } \\
\hline No. of facilities within 10 min walking distance & $-0.042^{*}$ & $-0.081,-0.002$ & $-0.039^{*}$ & $-0.076,-0.003$ & -0.031 & $-0.071,0.010$ \\
\hline Child can walk to school & -0.001 & $-0.040,-0.039$ & -0.019 & $-0.057,0.019$ & -0.010 & $-0.054,0.033$ \\
\hline Child can play outside with friends & 0.017 & $-0.022,0.056$ & 0.022 & $-0.014,0.058$ & $0.057^{* *}$ & $0.016,0.098$ \\
\hline Low traffic intensity & -0.029 & $-0.068,0.010$ & -0.030 & $-0.066,0.006$ & 0.013 & $-0.033,0.058$ \\
\hline Functionality $^{\mathrm{d}}$ & $-0.041^{*}$ & $-0.079,-0.003$ & $-0.036^{*}$ & $-0.072,-0.001$ & -0.035 & $-0.073,0.003$ \\
\hline Attractiveness & $-0.077^{* * *}$ & $-0.115,-0.040$ & $-0.071^{* * *}$ & $-0.105,-0.036$ & $-0.076 * *$ & $-0.116,-0.035$ \\
\hline \multicolumn{7}{|c|}{ Satisfaction with the neighborhood environment for child (low = reference) } \\
\hline Intermediate $^{\mathrm{a}}$ & -0.069 & $-0.157,0.020$ & -0.069 & $-0.153,0.014$ & -0.054 & $-0.148,0.040$ \\
\hline High $^{\mathrm{a}}$ & $-\mathbf{0 . 1 1 0}{ }^{*}$ & $-0.210,-0.009$ & $-\mathbf{0 . 1 3 3 ^ { * * }}$ & $-0.277,-0.038$ & -0.075 & $-0.192,0.042$ \\
\hline \multicolumn{7}{|l|}{ Social environment: } \\
\hline \multicolumn{7}{|l|}{ Social capital (low $=$ reference) } \\
\hline Medium $^{\mathrm{a}}$ & -0.067 & $-0.153,0.020$ & $-\mathbf{0 . 1 0 1}^{*}$ & $-0.183,-0.018$ & $-\mathbf{0 . 1 0 1}^{*}$ & $-0.183,-0.018$ \\
\hline High $^{\mathrm{a}, \mathrm{b}}$ & $-0.142^{* *}$ & $-0.247,-0.037$ & $-0.156^{* *}$ & $-0.254,-0.057$ & $-\mathbf{0 . 1 5 6}^{* *}$ & $-0.254,-0.057$ \\
\hline
\end{tabular}

* $\mathrm{p}<0.05$.

p** $<0.01$.

${ }^{* * *} \mathrm{p}<0.001, \beta$ is the standardized regression coefficient (unless indicated otherwise).

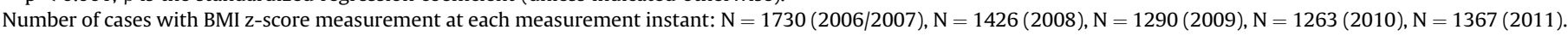

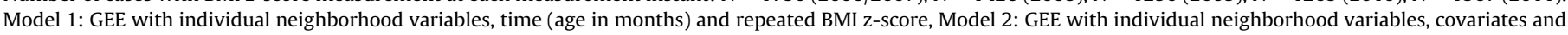

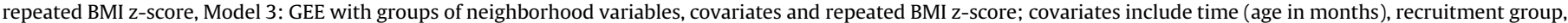

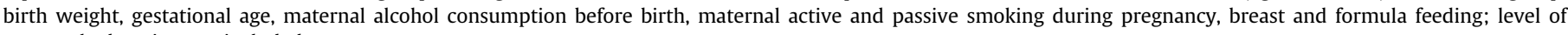
maternal education not included.

Significant results are additionally highlighted with bold letters.

${ }^{a}$ Unstandardized beta coefficient.

b Interaction with older siblings (Model 2).

c Interaction with gender (Model 2).

d Interaction with moving home (Model 2). 
the number of facilities or areas for exercise within 10 min walking distance, and functionality (Model 1 and 2), but in Model 3 they were not significant after adjusting for the other factors in the perceived physical environment domain. In the perceived social environment domain, social capital was inversely associated with BMI z-score in all models. BMI z-score consistently decreased with increasing social capital ( $\mathrm{p}=0.000)$, with a 0.156 lower BMI $\mathrm{z}$-score in the highest category (Model 2 and 3 ). The association between the neighborhood environment and BMI z-score did not differ by age since the interaction term included for child's age in months was not significant.

\subsection{Effect modification}

Cross-sectionally and longitudinally, there was effect modification when the child had an older siblings. In cross-sectional analyses, a statistically significant interaction was found for street lighting at night and older siblings in the adjusted model (Model 2). Stratified analysis indicated that for children with older siblings, a one standard deviation higher perception that street lighting is good was associated with a 0.077 lower BMI z-score (95\% CI: $-0.136,-0.019)$. For children without older siblings, the association was opposite but non-significant. Longitudinally, having older siblings was found to modify the association between the variables "nuisance/small scale crime do not make the neighborhood unsafe" in the adjusted model (Model 2). For children with older siblings, a one standard deviation increase in the variable was associated with a 0.057 lower BMI z-score (95\% CI: $-0.109,-0.005)$. Effect modification by older siblings was also found for social capital. Children with one or more older siblings had a 0.242 (95\% CI: $-0.377,-0.108)$ and a 0.166 (95\% CI: $-0.278,-0.054)$ lower BMI z-score in the highest and medium category of social capital, respectively, compared to the lowest category. In children who moved home, functionality was associated with a 0.136 (95\% CI: $-0.222,-0.050)$ lower BMI z-score.

Cross-sectionally, no effect modification by age at baseline was found, suggesting that the association between the neighborhood environment and BMI z-score did not differ depending on the child. Similarly, in the longitudinal analyses no significant interactions were found with the child's age in months, i.e., the time variable, and any of the neighborhood variables in the adjusted model. Therefore, the association of the neighborhood environment and the child's BMI z-score appeared to be constant over time in longitudinal analyses.

When the results of Model 3 in Table 2 were stratified by recruitment group, it appeared that the results for attractiveness were mainly determined by the conventional recruitment group (beta $-0.084,95 \% \mathrm{CI}-0.028,-0.140, \mathrm{p}=0.003$ ) whereas the results for outside play were mainly determined by the alternative recruitment group (beta $0.177,95 \%$ CI $0.066,0.289, \mathrm{p}=0.002$ ). Results for satisfaction in both recruitment groups were consistent with those of Model 3 in Table 2, but were not significant due to smaller numbers of subjects (intermediate satisfaction beta -0.109 , $95 \% \mathrm{CI}-0.230,0.012, \mathrm{p}=0.08$ in the conventional group; high satisfaction beta $-0.046,95 \% \mathrm{CI}-0.316,0.224, \mathrm{p}=0.07$ in the alternative group). The stratified results of the social environment were similar in both recruitment groups and of similar size as in Model 3 in Table 2 (high social capital: beta -0.145 , 95\% CI $-0.014,-0.276, \mathrm{p}=0.03$ in the conventional group; beta -0.126 , $95 \% \mathrm{CI}-0.413,0.161, \mathrm{p}=0.39$ in the alternative group). New associations with BMI z-score in the stratified analysis appeared only in the alternative recruitment group: child feels safe walking or cycling within neighborhood (beta $-0.115,95 \%$ CI -0.004 to $-0.226, \mathrm{p}=0.043$ ) and functionality (beta $-0.156,95 \% \mathrm{CI}$ $-0.045,-0.226), \mathrm{p}=0.006)$.

\section{Discussion}

This study sought to systematize multiple perceived neighborhood characteristics based on a conceptual model and explore their association with children's BMI in cross-sectional and longitudinal analyses. Furthermore this study included an examination of mediation, moderation and confounding factors in this relationship. The findings suggest that certain perceived physical as well as perceived social neighborhood characteristics are inversely associated with BMI z-score in children. Among the strongest and most robust factors were perceived attractiveness of the neighborhood, high satisfaction with the neighborhood environment, and social capital. One of the factors grouped under the domain of perceived safety were found to be associated with BMI z-score.

For the perceived physical environment, the findings showed that higher attractiveness was associated with lower BMI in children cross-sectionally and longitudinally. Previous research on this characteristic has yielded mixed results. One study found no association between perceived aesthetics of the neighborhood environment and BMI in 12 year-old girls (Evenson et al., 2007). Another study found that overweight in 5-18 year-olds was associated with living in neighborhoods with physical disorder, characterized as an observer reported indicator variable related to the upkeep and condition of the neighborhood (e.g., garbage, broken glass, condoms, drug use related items, cigarette butts) (Grafova, 2008). In two other studies, higher body weight in children was associated with lower availability of neighborhood greenness (Bell et al., 2008; Liu et al., 2007). In our study, attractiveness was a heterogeneous construct consisting of multiple items, namely the amount of green, litter, residential blocks, detached houses, dog feces and noise. Therefore, it included many of the aspects studied independently in previous research. While our operationalization of the construct is a more comprehensive assessment of attractiveness, linking our findings to previous research is difficult.

We found an inverse association between social capital and BMI cross-sectionally and longitudinally. Previous research on this characteristic has been theoretically and methodologically diverse, limiting the comparability. Franzini et al. (2009) explored the association between the indicators collective efficacy, collective socialization of children, social exchange, social contact, perceived safety and BMI in 11 year-old children. They observed a positive association between all indicators and physical activity, which in turn was inversely associated with BMI. Further, the indicator collective efficacy in Franzini's study (2009) was conceptualized similarly to social capital in our study. Another study defined social capital by an index combining variables that capture social cohesion, trust, and reciprocity and found that 10-17 year-old children were less likely to be obese in neighborhood environments with a higher social capital (Singh et al., 2008). Yet others have revealed alternate findings. One study looked at the impact of area-level mutual aid and social trust on BMI in 10-17 year-old children and adolescents, and found an inverse association that varied by age (McKay et al., 2007). Nonetheless, all of these studies involved cross-sectional designs, so causal inferences are not possible. One longitudinal study assessed the influence of social cohesion (e.g. trust, norms, exercise of sanctions), a group-level attribute of social capital, on child body weight, finding no relationship with weight gain in children (Carter et al., 2012). Although we found both crosssectional and longitudinal associations between social capital and BMI, these must be interpreted with caution, given our limitations in discerning additional longitudinal associations.

We found some evidence for an inverse association between satisfaction with the neighborhood environment and BMI z-score in children cross-sectionally and longitudinally. Satisfaction with the neighborhood environment was a construct including parents' 
perceptions of the child's opportunities to play, walk and cycle in the direct environment. Therefore, the construct constituted an overarching measure of the neighborhood environment, comprising latent characteristics like walkability, connectivity or functionality. Although it is impossible to pinpoint the precise characteristics creating satisfaction or dissatisfaction, this construct is useful to capture an overall tendency of the perceived suitability of the neighborhood for a child to move around. In the most comprehensive multiple regression model, the possibility of the child to play with friends was associated with a higher BMI z-score both cross-sectionally and longitudinally.

Longitudinally, we found that functionality of the neighborhood environment measured at baseline was inversely associated with BMI z-score in children who moved during follow-up. This means children of parents reporting a higher functionality at baseline (child's age 4-5 years before moving home), i.e., a neighborhood that is laid out in a child-friendly way, had a lower BMI z-score development over the 5 repeated measurements. Higher functionality may indicate a greater perceived need to keep pedestrians and cyclists away from motorized traffic due to more intensive traffic; which may be a reason for moving to a potentially even more child-friendly neighborhood. However, we found no strong associations with traffic intensity. Alternatively, we hypothesize that families moved home because of a new job or to reduce the distance to the workplace rather than concerns about the functionality of the neighborhood environment.

Only one association was found between variables related to perceived safety and BMI z-score. A systematic review found that studies pertaining to safety are characterized by different exposures of interest, population groups and study designs (Galvez et al., 2010). The authors noted that neighborhood safety constitutes a unique factor because it can be placed in both the social or built environment. We hypothesized finding a stronger association between perceived safety and BMI z-score than for the other constructs (Fig. 1), but the results run contrary. A recent study found that parental safety concerns were not associated with child's weight at age 5-6 years (Ferrao et al., 2013). Similarly, children's baseline age in our study was almost the same. Therefore, we speculate that children in this age group are not allowed to make use of their neighborhood by themselves, which may dampen the association between perceived safety and BMI z-score. This means that characteristics grouped under the domain of perceived safety may need to be operationalized through constructs assessing supervision in future studies. Moreover, there was a significant interaction between street lighting at night and having older siblings, which was associated with a lower BMI z-score. There might be an added effect of both characteristics in that parents allow their child to play outside if the lighting is good and in the presence of an older sibling.

Limitations of this study include theoretical and methodological shortcomings. We identify six main weaknesses. First, some environmental characteristics may not have been optimally placed in the conceptual model, which formed the strategy for statistical analyses. Nonetheless, our variable grouping choice was based on the themes of previous questionnaire and the methodological research. Second, there was no available information on food retail establishments and other neighborhood characteristics that related to energy intake through food, drinks, and snacking. Though in our study, energy balance-related behaviors are determined by energy intake as well as expenditure as indicated by our conceptual model (Fig. 1). Third, we did not include home environmental variables, which may be important explanatory variables for body weight in children in the age group under study. Fourth, some have cautioned against the importance of socioeconomic status in explaining part of the environment effect, suggesting it should be controlled for adequately (Dunton et al., 2009). In this study, we initially controlled for level of maternal education, which was later removed from the model since it did not show a relationship with child's BMI and did not confound the relation between the neighborhood and child's BMI. Fifth, we only had one measurement of the neighborhood environment and assume that the effect of the neighborhood characteristics on physical activity is reasonably stable at primary school age. This is clearly problematic for children who moved home during follow-up and for this reason we assessed effect modification by moving home. Finally, the BMI was based on the height and weight measured by parents, which has been found to be inaccurate in that weight tends to be underestimated and height appears to be overestimated (Dubois and Girard, 2007; Scholtens et al., 2007). This may have resulted in lower BMI measurements.

Major strengths of this study are the large number of neighborhood environmental characteristics and sample size included in the analysis, the cross-sectional and longitudinal design, and the strategic choice of covariates and statistical analyses based on a conceptual model. The importance of studying multiple neighborhood environment characteristics simultaneously has been highlighted because certain associations with built and social environmental characteristics may be non-negligible only when studied cumulatively (Casey et al., 2011). Only one study similar to ours has been published so far. Crawford et al. (2010) investigated the influence of home and neighborhood environment characteristics on 10-12 year-old children's physical activity and BMI z-score over 5 years using GEE. They found that home environment factors were more important in influencing children's BMI z-score than the neighborhood environment. In our context of the Netherlands, few homes have a swimming pool or a spa; however trampolines in the garden have become increasingly popular and are often shared with other children in the neighborhood. This illustrates the importance of environment on a small scale for this age group. Also, in the Netherlands distances between homes are small even in more rural communities. Clearly, this also highlights the importance of inter-country differences, which have been found to result in disparate effects of the neighborhood environment between countries, cultures and climates (Casey et al., 2011). Most studies to date have been undertaken in the United States. Therefore, our study based in the Netherlands adds to the variation in country contexts. Another major strength of our study is the inclusion of confounders and effect modifiers based on previous research. For example, we explicitly considered moving home in longitudinal analyses. A systematic review found that this aspect was only addressed by 5 of 27 studies included (Carter and Dubois, 2010). Moreover, direct measurement through questionnaires was used for data collection, which allowed respondents to provide information based on their perception of the neighborhood environment. This makes it possible to devise strategies tailored to this particular neighborhood. The importance of employing both direct and indirect measurement has been highlighted (Boehmer et al., 2007). Lastly, our conceptual model based on theoretical and empirical research was a useful tool to organize and analyze key variables systematically, which could be applied to future research or narrowed to other outcomes of interest like energy intake or energy expenditure.

\section{Conclusion}

In line with the theory-based conceptual model, this study found that perceived physical as well as social neighborhood environment characteristics are associated with BMI z-score in children cross-sectionally as well as longitudinally, adding to previous cross-sectional studies. No association has been found for 
safety of the neighborhood environment as perceived by the parents. In particular, attractiveness, satisfaction with the neighborhood environment, and social capital are inversely associated with child's BMI z-score cross-sectionally and longitudinally. Further research is warranted exploring differences between movers and non-movers, cumulative effects of and interdependencies between neighborhood environment characteristics. Targeted preventions programs and policies should be devised for characteristics showing the strongest associations with BMI z-score in children and those characteristics likely to be interrelated with them.

\section{Acknowledgments}

We thank the parents and children who participated in the KOALA study. The collection of environmental data in this study was financially supported by a collaborative grant from the Dutch Sugar Foundation and Friesland-Campina with support from the Ministry of Economic Affairs; the follow-up was supported by the Netherlands Asthma Fund (grant fund number 3.2.07.022 \& 3.2.03.48) and the Netherlands Heart Foundation (project number 2008B112). The funding organizations had no influence on the design, analysis and reporting of the present study.

\section{References}

Addy, C.L., Wilson, D.K., Kirtland, K.A., Ainsworth, B.E., Sharpe, P., Kimsey, D., 2004. Associations of perceived social and physical environmental supports with physical activity and walking behavior. Am. J. Public Health 94, 440-443.

Bell, J.F., Wilson, J.S., Liu, G.C., 2008. Neighborhood greenness and 2-year changes in body mass index of children and youth. Am. J. Prev. Med. 35, 547-553.

Black, J.L., Macinko, J., 2008. Neighborhoods and obesity. Nutr. Rev. 66, 2-20.

Boehmer, T.K., Hoehner, C.M., Deshpande, A.D., Ramirez, L.K.B., Brownson, R.C., 2007. Perceived and observed neighborhood indicators of obesity among urban adults. Int. J. Obes. (Lond.) 31, 968-977.

Booth, K.M., Pinkston, M.M., Poston, W.S., 2005. Obesity and the built environment. J. Am. Diet. Assoc. 105, 110-117.

Brownson, R.C., Chang, J.J., Eyler, A.A., Ainsworth, B.E., Kirtland, K.A., Saelens, B.E., et al., 2004. Measuring the environment for friendliness toward physical activity: a comparison of the reliability of 3 questionnaires. Am. J. Public Health $94,473-483$.

Carter, M.A., Dubois, L., 2010. Neighbourhoods and child adiposity: a critical appraisal of the literature. Health \& Place 16, 616-628.

Carter, M.A., Dubois, L., Tremblay, M.S., Taljaard, M., Jones, B.L., Newton, R.L., 2012. Trajectories of childhood weight gain: the relative importance of local environment versus individual social and early life factors. PLoS One 7,1-12.

Casey, R., Oppert, J.-M., Weber, C., Charreire, H., Salze, P., Badariotti, D., et al., 2011. Determinants of childhood obesity: what can we learn from built environment studies? Food Qual. Prefer. http://dx.doi.org/10.1016/j.foodqual.2011.06.003.

Cervero, R., Duncan, M., 2003. Walking, bicycling, and urban landscapes: evidence from the San Francisco Bay area. Am. J. Public Health 93, 1478-1483.

Crane, R., Crepeau, R., 1998. Does neighborhood design influence travel?: a behavioural analysis of travel diary and GIS data. Transp. Res. Part D: Transp. Environ. 3, 225-238.

Crawford, D., Cleland, V., Timperio, A., Salmon, J., Andrianopoulos, N., Roberts, R., et al., 2010. The longitudinal influence of home and neighbourhood environments on children's body mass index and physical activity over 5 years: the CLAN study. Int. J. Obes. (Lond.) 34, 1177-1187.

Dietz, W.H., 1994. Critical periods in childhood for the development of obesity. Am. J. Clin. Nutr. 59, 955-959.

Dubois, L., Girard, M., 2006. Early determinants of overweight at 4.5 years in a population-based longitudinal study. Int. J. Obes. (Lond.) 30, 610-617.

Dubois, L., Girard, M., 2007. Accuracy of maternal reports of prescholers' weights and heights as estimates of BMI values. Int. J. Epidemiol. 36, 132-138.
Dunton, G.F., Kaplan, J., Wolch, J., Jerrett, M., Reynolds, K.D., 2009. Physical environmental correlates of childhood obesity: a systematic review. Obes. Rev. 10, 393-402.

Evenson, K.R., Scott, M.M., Cohen, D.A., Voorhees, C.C., 2007. Girls' perception of neighborhood factors on physical activity, sedentary behavior, and BMI. Obesity $15,430-445$.

Feng, J., Glass, T.A., Curriero, F.C., Stewart, W.F., Schwartz, B.S., 2010. The built environment and obesity: a systematic review of the epidemiologic evidence. Health \& Place 16, 175-190.

Ferrao, M.M., Gama, A., Marques, V.R., Mendes, L.L., Mourao, I., Nogueira, H., et al., 2013. Association between parental perceptions of residential neighbourhood environments and childhood obesity in Porto, Portugal. Eur. J. Public Health.

Field, A., 2009. Discovering Statistics Using SPSS. SAGE Publications Ltd, London.

Foster, S., Giles-Corti, B., 2008. The built environment, neighborhood crime and constrained physical activity: an exploration of inconsistent findings. Prev. Med. 47, 241-251.

Franzini, L., Elliott, M.N., Cuccaro, P., Schuster, M., Gilliland, M.J., Grunbaum, J.A. et al., 2009. Influences of physical and social neighborhood environments on children's physical activity and obesity. Am. J. Public Health 99, 271-278.

Fredriks, A.M., Van Buuren, S., Wit, J.M., Verloove-Vanhorick, S.P., 2000. Body index measurements in 1996-7 compared with 1980. Arch. Dis. Child. 82, 107-112.

Galvez, M.P., Pearl, M., Yen, I.H., 2010. Childhood obesity and the built environment: a review of the literature from 2008-2009. Curr. Opin. Pediatr. 22, 202-207.

Giles-Corti, B., Donovan, R.J., 2003. Relative influences of individual, social environmental, and physical environmental correlates of walking. Am. J. Public Health 93, 1583-1589.

Grafova, I.B., 2008. Overweight children: assessing the contribution of the built environment. Prev. Med. 47, 304-308.

Kirtland, K.A., Porter, D.E., Addy, C.L., Neet, M.J., Williams, J.E., Sharpe, P.A., et al. 2003. Environmental measures of physical activity supports: perception versus reality. Am. J. Prev. Med. 24, 323-331.

Kleinbaum, D.G., Kupper, L.L., Muller, K.E., 2008. Applied Regression Analysis and Other Multivariable Models. Thompson Higher Education, Belmont.

Kremers, S.P., de Bruijn, G.J., Visscher, T.L., van Mechelen, W., de Vries, N.K., Brug, J., 2006. Environmental influences on energy balance-related behaviors: a dualprocess view. Int. J. Behav. Nutr. Phys. Act. 3, 9.

Kummeling, I., Thijs, C., Penders, J., Snijders, B.E.P., Stelma, F., Reimerink, J., et al., 2005. Etiology of atopy in infancy: the KOALA Birth Cohort Study. Pediatr. Allergy Immunol. 16, 679-684.

Law, C., Power, C., Graham, H., Merrick, D., 2007. Obesity and health inequalities. Obes. Rev. 8, 19-22.

Liang, K.-Y., Zeger, S.L., 1986. Longitudinal data analysis using generalized linear models. Biometrika 73, 13-22.

Liu, G.C., Wilson, J.S., Qi, R., Ying, J., 2007. Green neighborhoods, food retails and childhood overweight: differences by population density. Am. J. Health Promot. 21, 317-325.

McKay, C.M., Bell-Ellison, B.A., Wallace, K., Ferron, J.M., 2007. A multilevel study of the associations between economic and social context, stage of adolescence, and physical activity and body mass index. Pediatrics 119, S84-S91.

Oken, E., Gillman, M.W., 2003. Fetal origins of obesity. Obes. Res. 11, 496-506.

Power, C., Jefferis, B.J., 2002. Fetal environment and subsequent obesity: a study of maternal smoking. Int. J. Epidemiol. 31, 413-419.

Rolland-Cachera, M.F., Péneau, S., 2013. Growth trajectories associated with adult obesity. World Rev. Nutr. Diet. 106, 127-134.

Rothman, K.J., Greenland, S., Lash, T.L., 2008. Modern Epidemiology. Lippincott Williams \& Wilkins, Philadelphia.

Safron, M., Cislak, A., Gaspar, T., Luszczynska, A., 2011. Micro-environmental characteristics related to body weight, diet, and physical activity in children and adolescents: a systematic umbrella review. Int. J. Environ. Health Res. 21, 317-330.

Scholtens, S., Brunekreef, B., Visscher, T.L.S., Smit, H.A., Kerkhof, M., De Jongste, J.C., et al., 2007. Reported versus measured body weight and height of 4-year-old children and the prevalence of overweight. Eur. J. Public Health 17, 369-374.

Singh, G.K., Kogan, M.D., Dyck, P.C.V., 2008. A multilevel analysis of state and regional disparities in childhood and adolescent obesity in the United States. J. Commun. Health 33, 90-102.

Twisk, J.W.R., 2006. Applied Longitudinal Data Analysis for Epidemiology: a Practical Guide. Cambridge University Press, Cambridge.

Yen, I.H., Syme, S.L., 1999. The social environment and health: a discussion of the epidemiologic literature. Annu Rev. Public Health 20, 287-308. 